\title{
A CRITICAL ANALYSIS OF SELECTED ASPECTS OF THE SOUTH AFRICAN LEGAL FRAMEWORK PERTAINING TO CHILDREN LIVING IN PRISON WITH THEIR MOTHERS - WITH BRIEF COMPARATIVE COMMENTS
}

\author{
Meda Couzens \\ Law MA LLM MChPr \\ Senior lecturer, School of Law \\ University of KwaZulu-Natal, Durban \\ Nicole Mazoue \\ BPrimEd MChPr
}

\section{SUMMARY}

This article contains a critical analysis of the South African legal framework applicable to children living in prison with their mothers. It focuses on aspects which the authors believe to be problematic in the legal framework, namely the procedure for the admission of children in prison with their mothers, the separation of children from their incarcerated mothers and the gender implications of the legal framework. Recommendations for improving the current legal framework are made based on a comparative assessment of the South African framework against the relevant policies in England and Western Australia.

\section{INTRODUCTION}

Allowing children to live in prison with their mothers is a difficult decision, and legitimate concerns have been raised - both by those in favour of it, and against it. ${ }^{1}$ South Africa has made a policy decision to allow mothers to apply

In the course of her studies for the masters programme, this author completed a minidissertation entitled Children Incarcerated with Their Mothers: A Critique of the Current AgeBased Approach to the Separation of Children from Their Mothers. Some of the aspects explored in this article derive from this mini-dissertation. We would like to thank Mr David Barraclough for his assistance with the editing of this article.

Authors in favour of allowing children to join their mothers in prison, include: Goshin and Byrne "Converging streams of Opportunity for Prison Nursery Programs in the United States" 2009 48(4) Journal of Offender Rehabilitation 271; and Munro "The Emerging 
for permission to bring their children into prison under certain conditions, and for a limited period of time. To this effect, the relevant South African authorities have drafted the legal framework, which is analysed in this article. The content of this framework has been subject to limited study previously, and this article addresses this gap in published research. ${ }^{2}$ The article has a limited focus, and analyses only the procedure for the admission of children with their mothers in prison, the separation of the child residing with his/her mother into prison from the mother concerned, and the gender aspect of the legal framework. We consider that these are areas where the South African policy has weaknesses, which should be addressed when the policy framework is revised. In order to provide informed recommendations for future legal and policy reform, we briefly consider the relevant policies applicable in England and the state of Western Australia. The two foreign legal frameworks contain useful approaches to the issues identified as problematic in the South African framework.

For the purpose of this article, the legal framework pertaining to children of incarcerated mothers includes the Correctional Services Act 111 of 1998 (the Act), as amended by the Correctional Services Amendment Act 25 of 2008 (the Amendment Act), and the Department of Correctional Services BOrder 1 Chapter 21: Infants and Mothers (the B-Order 1) and the Infants and Mothers Policy (the Policy). ${ }^{3}$

The statutory framework for the drafting and the implementation of the policies applicable to children living with their mothers in prison is section 20 of the Act, as amended, which provides:

"Mothers of young children

20. (1) A female inmate may be permitted, subject to such conditions as may be prescribed by regulation, to have her child with her until such child is two years of age or until such time that the child can be appropriately placed taking into consideration the best interest of the child.

(1A) Upon admission of such a female inmate the Department must immediately, in conjunction with the Department of Social Development, take

Rights of Imprisoned Mothers and Their Children" 2002 14(3) Child and Family Law Quarterly 303. Examples of authors against allowing children joining their mothers in prison, or allowing it in very limited circumstances or for a very short period of time, include: Robertson "Children Imprisoned by Circumstance" 2008 Quaker United Nations Office: Human Rights and Refugee Programme www.quno.org (accessed 2011-10-02); Hesselink and Dastile "The Reality of Babies and Toddlers Behind Bars" 2010 23(1) Acta Criminologica 65; and Schoeman "Babies Behind Bars - Hidden Victims of Policy and Practice" 2011 12(2) Child Abuse Research: A South African Journal 77.

2 Valuable field research has been conducted into how children and their mothers live in the South African correctional services centres that accommodate them. Eg, Hesselink and Dastile 2010 23(1) Acta Criminologica 65; Luyt and du Preez "A Case Study of Female Incarceration in South Africa" 2010 23(3) Acta Criminologica 88; Schoeman and Basson "The Influence of Imprisonment on Infants and Young Children Incarcerated with their Mothers" 2009 (NICRO) http://www.nicro.org.za/wp-content/uploads/2011/08/Babies-behind -bars-summary.pdf (accessed 2013-03-19); and Schoeman 2011 12(2) Child Abuse Research: A South African Journal 84.

3 Both these documents are on file with the authors. They were obtained by the second author by email from DCS officials in February 2012. The Policy was approved in the cycle 2007/2008 DCS Annual Report http://www.dcs.gov.za/Publications/Annual\%20Reports/ DCS\%20Annual\%20Report\%202008.pdf (accessed 2013-05-19) 56. 
the necessary steps to facilitate the process for the proper placement of such a child.

(2) The Department is responsible for food, clothing, health care and facilities for the sound development of the child for the period that such child remains in prison.

(3) Where practicable, the National Commissioner must ensure that a mother and child unit is available for the accommodation of female inmates and the children whom they may be permitted to have with them."

This section of the Act applies both to sentenced and unsentenced female prisoners. ${ }^{4}$ The offence committed by the mother does not seem to disqualify her automatically from keeping the child with her in prison. ${ }^{5}$ The essence of section 20 of the Act can be summarized as follows: incarcerated mothers may be permitted to keep their children with them until the child is two years of age, or until an appropriate alternative placement can be found. Admission of the child with the mother in prison is considered a temporary measure - pending more suitable arrangements. The Act does not require that the housing of mothers with babies takes place only in centres where a mother-and-child unit exists. It requires though, that the National Commissioner ensures the existence of such units "where practicable". Further provisions pertaining to incarcerated mothers and their children are contained in B-Order 1 , which is mentioned above.

In the next section, the article discusses the procedure for the admission of a child with his/her mother in prison, and then reviews the separation of the child from his/her mother and the placement in alternative care. Section 4 contains a critical analysis of the gender aspects of the legal framework, while section 5 reviews the English and Western Australian policies, and presents comparative comments. In the conclusion, some recommendations for legal reform are made.

\section{ADMISSION OF A CHILD TO BE IN PRISON WITH THE MOTHER}

Not many mothers have chosen to have their young children join them in custody. As at 31 March 2010, there were 129 babies and infants in prison with their mothers. ${ }^{6}$ In September 2009, the number was higher - at $168 .^{7}$ In the early 2000s, the numbers were even higher, with 224 babies living in prison on 31 March 2001, and 194 on 31 March 2002. ${ }^{8}$ Some children are

4 See the definition of "inmate" in s 1 of the Act. Regulation 10.1.1 also indicates that this provision applies to sentenced, as well as unsentenced prisoners. See Correctional Services Regulations R323 published in GG 35277 of 2012-04-25.

5 Presumably offences related to the well-being of the child would lead to the child being potentially declared in need of care and protection, and this might result in the separation from the mother and care measures being implemented.

6 DCS “Annual Report 2009/2010" http://www.dcs.gov.za/Publications/Annual\%20Reports/ DCS\%20Annual\%20Report\%202010.pdf (accessed 2013-02-05) [23].

7 Keynote Address by Correctional Services Deputy Minister, Ms Hlengiwe Mkhize, MP, during The Introduction of the Imbeleko Project, Durban Westville Correctional Centre, 18 September 2009 http://www.dcs.gov.za/News/Speeches.aspx (accessed 2013-02-05).

8 DCS “Annual Report 2001/2002" http://www.dcs.gov.za/Publications/Annual\%20Reports/ DCS\%20Annual\%20Report\%202002.pdf (accessed 2013-02-05). 
born in prison, while some are allowed in to be with their mothers. ${ }^{9}$ Among the factors associated with mothers' decisions to bring their children in jail, previous research has indicated the following: "lack of supervision for the child in open society", ${ }^{10}$ mothers' lack of information about possible placement options; ${ }^{11}$ and difficulties in arranging alternative care for their children. ${ }^{12}$ It has also been suggested that some women commit petty crimes in order to get a custodial sentence, and to obtain access to better health care, food and clothing. ${ }^{13} \mathrm{~A}$ study conducted by Luyt and du Preez on a sample of 33 females incarcerated with their children, showed that most participants were not married to the biological father of the child, ${ }^{14}$ and thus could not rely on their partners to take over child-rearing responsibilities.

Strikingly, section 20 of the Act does not define the term "mother", and thus it is unclear whether the Act applies also to adoptive or foster mothers, and female primary carers. ${ }^{15}$ The Infants and Mothers Policy requires that a female offender applies in writing to keep her infant with her in prison; ${ }^{16}$ the female prisoner must also indicate in writing if she prefers the child to remain outside prison. ${ }^{17}$ Although the mother's request seems to initiate the admission process, the policy documents state that "[t]he needs of the infants should be regarded as first priority", since this is not "an amenity for the mother" ${ }^{18}$ It is acknowledged, however, that the admission of a mother

9 Twenty of the children were born while the mother was incarcerated and 13 before incarceration (Luyt and du Preez 2010 23(3) Acta Criminologica 107). The 2001/2002 DCS Annual Report indicated that only three and four babies were born in prison in 2001 and 2002, respectively (see fn 8 above).

10 Luyt and du Preez 2010 23(3) Acta Criminologica 107.

11 Schoeman and Basson 2009 (NICRO) http://www.nicro.org.za/wp-content/uploads/2011/08/ Babies-behind-bars-summary.pdf 2.

12 Schoeman and Basson 2009 (NICRO) http://www.nicro.org.za/wp-content/uploads/2011/08/ Babies-behind-bars-summary.pdf 15.

13 A Corrections Coordinator of the Pretoria Female Correctional Centre stated that "it is known that some pregnant females commit petty crimes such as shoplifting prior to the birth of their babies". By doing this "the pregnant mother receives a lighter sentence, and she knows that she will receive adequate to good medical care and regular access to such medical services during the birth of her baby" (Hesselink and Dastile 2010 23(1) Acta Criminologica 66). Hesselink and Dastille suggest that some impoverished mothers might thus perceive a period in a South African prison as an opportunity to access better nutrition, clothing and health care for herself and her baby - than she would have been able to provide on the outside (Hesselink and Dastile 2010 23(1) Acta Criminologica 66). Based on the high levels of poverty in South Africa, many infants who reside in South African prisons might get better food, clothing and health care than they would have in the community (Schoeman and Basson 2009 (NICRO) http://www.nicro.org.za/wp-content/uploads/2011/ 08/Babies-behind-bars-summary.pdf 13).

14 Luyt and du Preez 2010 23(3) Acta Criminologica 107.

15 It is even less clear whether $s 20$ of the Act applies to primary caregivers who are not the mothers of the children they care for. The primary caregiver aspect is discussed further in section 4 and then with reference to the Western Australian policy in s 5.

16 Par 9.1.1. B-Order 1; and Par 7.9 of the Infants and Mothers Policy.

17 Par 9.1.1. B-Order 1.

18 Par 3.3. B-Order 1. Par 3.4. B-Order 1 indicates, however, that the admission with a child is also seen by the Department as an opportunity to reduce the likelihood of the mother lapsing into crime - by helping her develop a positive relationship with the child, and providing opportunities for self-development. There are privileges derived by the mother from the presence of her infant with her in a prison, such as special care before and after birth (par 10.2. B-Order 1 being entitled not to be transferred to another correctional centre if the health of the child does not allow for such (par 10.3. B-Order 1); personal care for the 
together with her child creates the opportunity to reduce the likelihood of the mother lapsing into crime - by helping the mother to develop a positive relationship with her child and by providing opportunities for selfdevelopment. ${ }^{19}$ Whether a child is to remain with the mother in prison or not, seems to be decided by a multi-disciplinary team which analyses the interests of the child. The membership of this team is not specified in any of the relevant documents.

The criteria for admission of children in prison with their mothers are not extensively dealt with in the relevant legal instruments. The Act simply states that "a female inmate may be permitted [to bring a young child into prison], subject to such conditions as may be prescribed by regulation". ${ }^{20}$ However, the Regulations are silent on the issue. ${ }^{21}$ More details are to be found in BOrder 1 and the Policy. Three admission criteria can be identified: the length of the mother's sentence, the availability of suitable care in the community, and the age of the child. As far as the length of the mother's sentence is concerned, the policies indicate that if the length of the sentence is such that it is likely that the mother and the child will eventually be separated, the multi-disciplinary team establishes whether it is in the child's interest to remain with the mother for some time, or to be immediately separated from her. $^{22}$

A child will only be admitted with his/her mother in prison "when no other suitable accommodation and care are available at that point". ${ }^{23}$ The emphasis on "suitability" of accommodation and care for the infant seems to disregard the special relationship between a mother and a very young child, and places the relevant factors outside of this relationship. The phrase "suitable accommodation and care" says nothing about the threshold of suitability of alternative care (that is, family-type care versus institutional care); or put differently, it does not indicate the availability of what forms of care gives DCS legitimate grounds to reject a mother's application to bring her child to be with her in prison. It is also not clear in the regulatory framework how the availability, or otherwise, of suitable care is established, and whether it involves an investigation by social workers, or whether a simple statement by the mother will suffice. If no social work investigation takes place, the $S$ v M (Centre for Child Law as Amicus Curiae) ${ }^{24}$ precedent becomes very important. This case establishes that sentencing officers have an obligation to inquire about the impact of a potential imprisonment on the children of an offender - who is the primary caregiver. ${ }^{25}$ The report obtained by the judicial officers to ascertain the impact of incarceration of a primary caregiver on children, would be extremely useful to DCS officials who are responsible for making the decision about admitting a child with his/her mother in a correctional centre. Since such a report has become compulsory

child on a full-time basis for the first three months of a child's life (par 12.1. B-Order 1); and a special diet for pregnant and lactating prisoners (par 13.3. B-Order 1).

19

Par 3.4. B-Order 1.

S 20(1) of the Act.

Correctional Services Regulations R323 published in GG 35277 of 2012-04-25.

Par 14.4. B-Order 1.

Par 3.0. B-Order 1.

2008 (3) SA 232 (CC).

$S \vee M$ supra par 32 and 33. 
in the sentencing process, arguably, another report by social services would be unnecessary. However, the DCS officials need to be aware of the existence of such reports, and need to consider them when deciding on the admission of the child. Another unclear aspect is who is responsible for identifying alternative care options for the child prior to the mother's incarceration, and more specifically, whether this rests with the mother or with the state.

The age of the child is another factor in establishing whether the mother should be allowed to bring a child to be with her in prison. Although section 20 of the Act refers to "young children" and the B-Order 1 refers to "infants", the definitions converge in that the upper-age limit for a child to be admitted and/or to remain in prison with his/her mother, is the age of two. B-Order 1 defines an infant as "a person from birth to 2 years, who is dependent on his/her mother's care, whilst the mother is in custody". ${ }^{26}$ Of note is the emphasis, in the latter definition, on the dependency of the child on his/her mother. The meaning of "dependent" on mother's care is not explained in the policies, but it echoes the primary-caregiver approach utilized by courts in the sentencing process. ${ }^{27}$ This interpretation might be reinforced by the fact that the presence of a father in the child's life does not seem to be an impediment to admitting children to be with their mothers in prison. ${ }^{28}$ Neither the Act nor the policies mention the opinions and wishes of the father (or other relatives) in the decision-making process - despite the policies being predicated on the principle of family-centredness. ${ }^{29}$ This disregards the new trend in South African family law which promotes cooperative parenting between parents holding parental responsibilities. ${ }^{30}$ However, it needs to be considered that many South African children are raised without their fathers playing a role in their upbringing. ${ }^{31}$ This aspect should be acknowledged in the policies, and a distinction should be drawn between the potential involvement in the decision-making of fathers with, and without, parental responsibilities.

It is not clear what weight is currently given to the mother being the primary caregiver or not. There is no indication that not being the primary caregiver of the child would disqualify the mother from bringing her child to be with her in prison. However, we consider that this aspect should not be neglected by the decision-makers, because the very premise of the admission of a child to be with his/her mother in prison is to protect (or to

26 Par 2.0. B-Order 1.

27 S v M supra 261; MS v S (Centre for Child Law as Amicus Curiae) [2011] (2) SACR 88 (CC); and S v Howells 1999 (1) SACR 675 (C).

28 Par 12.4. B-Order 1. To this extent, the approach departs from the sentencing jurisprudence, which indicates that the existence of another resident parent, willing to take charge of children's upbringing, would permit the imposition of a custodial sentence $(S \vee S$ (Centre for Child Law as Amicus Curiae) 2011 (7) BCLR 740 (CC)). S v S supra suggests a distinction between residents and non-resident parents.

29 Par 1.2.3. B-Order 1 which indicates that "The family should be motivated to be actively involved as far as possible." See also par 7.3 in the Infants and Mothers Policy.

30 Chapter 3 of the Children's Act, especially s 20-21.

31 A South African Institute for Race Relations study showed that the proportion of living, but absent, fathers was 48\% in 2009 (Holborn and Eddy "First Steps to Healing the South African Family" 2011 http://www.sairr.org.za/services/publications/occasional-reports/files/ first-steps-to-healing-the-south-african-family-final-report-mar-2011.pdf [4]. 
facilitate the creation of) the special bond between mother and child. Indeed, the definition of the "infant" above indicates that the dependency of the child is defined narrowly in relation to his/her mother ("dependent on his/her mother's care"), and not in abstracto.

Strikingly, the legal framework does not require that a decision to admit a child to join the mother in prison be made giving paramount consideration to the best interests of the child. ${ }^{32}$ It is not clear whether this is an unintended omission of the policy-makers, or a deliberate move designed to indicate that the admission with the mother is not a right of the child - but a measure in which the DCS has a wide degree of discretion. Regardless of this omission, the decision-makers have a constitutional and statutory obligation to consider the best interests of the child. ${ }^{33}$ An explicit requirement in this regard would have been desirable and would have clarified that, although inter-related, the interests of children and their mothers remain distinct. The current framework raises the concern that the policy-makers operate on the presumption that a mother would only make an application to have her child admitted to be with her in prison, if that was in the best interests of her child. This assumption can be questioned. It is debatable, for example, whether mothers have a full understanding of the prison environment, ${ }^{34}$ its impact on both the mother and the child, and the quality of their interaction.

Another notable omission from the admission criteria is the quality of the environment which the DCS can make available for children and their mothers. The current legal framework allows for mothers and their children to be placed either in a mother-and-child unit, ${ }^{35}$ or outside such units - but in a "humane environment and taking into consideration their specific needs". The Committee on the Rights of the Child - which monitors the implementation of the 1989 UN Convention on the Rights of the Child, to which South Africa is a party - has recommended that the conditions of incarceration be taken into account in establishing whether it is in the child's interests to be admitted to be in custody with the mother. ${ }^{37}$ Arguably, not considering the quality of the environment which the DCS can offer de facto to a child who is admitted to be with a mother in a specific correctional

32 The standard is included as an explicit criterion for decisions pertaining to placement (par 15.1. B-Order 1.); permanency planning (B-Order 1. par 1.2.7.); maintaining contact and fostering the relationship between mother and child after the child's placement outside the prison (B-Order 1. par 15.11.).

$33 \mathrm{~S} 28(2)$ of the Constitution.

34 Par 9.1 of B-Order 1, requires that the mother is informed and accepts the conditions of accommodation and care. The Order does not specify, however, who the responsible official is for providing the information.

35 S 20(3) of the Act indicates that "where practicable" the National Commissioner should ensure the existence of mother-and-child units. The reference to "where practicable" indicates that a mother-and-baby unit is not the sole option for accommodating mothers and their babies.

36 Par 4.5 of B-Order 1 reads: "Where a correctional centre/prison does not provide for a mother-and-child unit/single accommodation for a mother and her child, the Head of the Prison/correctional centre is responsible for initiating satisfactory arrangements to accommodate them in a humane environment and taking into consideration their specific needs, i.e. privacy."

37 Committee on the Rights of the Child "Report and Recommendations of the Day of General Discussion on Children of Incarcerated parents" $2011 \mathrm{http}: / /$ www2.ohchr.org/english/bodies/ crc/docs/discussion/2011CRCDGDReport.pdf (accessed 2013-03-19) [par 37]. 
centre, would mean that decisions that are best for children are not necessarily made.$^{38}$ Previous research indicates that there is a gap between policy and its implementation, and allowing children to live in an inadequate prison environment may have a negative impact on a child's development. ${ }^{39}$ We believe the DCS ought to acknowledge the limitations of the facilities it can provide, and communicate those to the mother. Whilst this might be prejudicial to the image of the DCS, it is a price which the Department needs to pay - should it remain faithful to the constitutional imperative of making decisions respecting the best interests of children.

The Policy and the B-Order 1 are weak with regard to the avenues available to the mother should she want to challenge a decision by the DCS not to allow the child to join her in prison. No specific provision deals with the mother's option to appeal a decision of not to allow her child to join her in prison. The default position is that the mother needs to use the normal complaints and request procedure regulated by section 21 of the Act, and to appeal to two administrative levels within the correctional services system (the Head of the Correctional Centre and the National Commissioner) - and then further to an Independent Correctional Services Centre Visitor. There does not seem to be an explicit requirement for the involvement of the judiciary in the process of admission. However, the mother could challenge the Correctional Services' decision by invoking the right to just administrative action $^{40}$ in the relevant High Court. The policies refer explicitly to the involvement of the judiciary, only "where problems are experienced" in the placement of the child outside of prison or in cases of urgent placement. Thus:

"At correctional centres/prisons where problems are experienced, or where the placement of the infant is urgent, the information must be submitted to the local Commissioner of Child Welfare. Where necessary he is also responsible for the immediate removal of the infant to a place of safety until such time as the infant can be placed."

38 The DCS is bound to make decisions giving paramount importance to the best interests of the child, as required by s 28(2) read with s 8(1) of the Constitution.

39 On 18 August 2011 South Africa opened its first mother and baby unit (MBU) at Pollsmoor prison in Cape Town. The second MBU was launched on 26 August 2011 at the DurbanWestville Correctional centre. A further three similar facilities are expected to be created in the Gauteng, Free State and Eastern Cape. The policies contain comprehensive requirements for the setting up of a MBU, which includes the provision of a lawn or synthetic grass, and a sandpit with sterilized sand and plants in the unit (par 4.3. B Order 1.), and baby baths (par 6.0. B Order 1.). However, such facilities are sometimes lacking (Luyt and du Preez 201023 (3) Acta Criminologica 107). Although the Act indicates that the DCS is responsible for clothing (s 20(2), according to one study the DCS provides only the first round of clothing - after which the mother has to obtain clothing supplies (Luyt and du Preez 2010 23(3) Acta Criminologica 107).

40 S 33 of the Constitution; and s 6 of the Promotion of Administrative Justice Act 3 of 2000.

41 Par 15.8. B-Order 1. It is the responsibility of the DCS to inform the children's court when "problems are experienced" in the placement process. The policies give no indication, however, of the type of "problems" which generate the obligation of the DCS to inform the children's court. Given the seriousness of the issue - the separation of the child from his/her primary caregiver - the DCS should be cautious and give a wide interpretation to the term "problems". Examples of cases which should reach the children's court could be where there is disagreement between the mother and DCS officials regarding the time of separation, type of placement, or the person in whose care the child will be placed. 
The cited provision seems to be applicable exclusively to "problems" which occur when arranging the placement of the child, or when the child needs to be removed urgently from the mother. It does not seem to be applicable to a negative decision relating to the admission of the child. ${ }^{42}$ Arguably - for a child whose mother is incarcerated - a refusal to permit $\mathrm{him} / \mathrm{her}$ to join the mother in prison constitutes interference with the right to parental care and giving paramount important to the best interests of the child. We believe it is problematic that the policies are not consistent with regard to the intervention of the judiciary. The reason for the lack of symmetry in the legal protection against the separation of the child from his/her mother at the time of admission or placement respectively - is not apparent. A decision not to admit the child to be with the mother in prison has the same effect on the relationship between the mother and the child and ultimately on the child's right to parental care - as a decision to separate a child already residing with the mother in prison.

On the strength of the Constitutional Court decision in $C v$ Department of Health and Social Development, Gauteng ( $C \vee$ Department of Health) ${ }^{43}$ it can be argued that a decision by DCS officials to separate the mother and the child - whether this occurs as a result of declining the mother's request to have the child admitted, or as a result of the placement outside the prison of a child already living with his/her mother in a prison - should be automatically reviewable by a children's court in the presence of the mother and the child. ${ }^{44}$ Although the decision in the above case dealt with the emergency removal of a child from his/her family environment, there are some similarities with the situation of incarcerated mothers. The reason for the declaration of invalidity, according to the majority, was that the emergency separation of parents and children in the absence of an automatic judicial review in a reasonable period of time - in the presence of parents and their children - was contrary to section 28(2) of the Constitution. ${ }^{45}$ Although certain possibilities to challenge the removal were present, such as the exercise of the right in section 33 of the Constitution, these were seen as ineffective given the vulnerability of the parents involved. ${ }^{46}$ In the majority's view, the automatic judicial review of the emergency removals was the only adequate remedy to ensure legislation complied with section 28(2) of the Constitution, and that children are not unduly separated from their families. ${ }^{47}$

The application of the $C$ case to the current context, achieves the same effect with a compulsory referral to a children's court as a result of compliance with paragraph 15.8 of B-Order 1 - in the context of a contested

42 Par 15 of B-Order 1 is titled "Placement of infants".

432012 (2) SA 208 (CC).

44 This case dealt with the emergency removals of children from the care of their parents. One of the aspects of the decision was that such removals must be automatically reviewed by the children's courts, in the presence the children and their parents. In $C v$ Department of Health supra the court did not explore the issue of legal representation of the children. Most likely, such representation will be inevitable in such cases - given both the potential conflict of interest between the mother and the child, and the young age of the child.

45 C v Department of Health supra par 77 per Yacoob (majority judgment); and par 27 per Skweyiya J (concurring judgment).

46 Par 37 per Skweyiya J.

47 Par 79 per Yacoob J. 
placement of a child outside the prison. However, the precedent in $C v$ Department of Health might be useful in the context of a DCS refusal to admit the child to be with the mother in prison. In $C v$ Department of Health, the vulnerability of the parents involved, as well as that of their children, were factors contributing to the court deciding that an automatic judicial review by a children's court of an emergency removal - should occur. No doubt inmate mothers and their children are equally vulnerable, and one can make the argument that an automatic judicial review should also occur in these circumstances. Such a position resonates with the recommendations of the Committee on the Rights of the Child, which suggested that decisions regarding the admission of a child to be with a mother in prison should be made "with an option for judicial review".

\section{SEPARATION AND PLACEMENT}

The separation of a mother from her child is generally a difficult experience. The circumstances of children living in prison with their mothers make this separation traumatic:

"In the case where a child who stayed with his/her imprisoned mother is separated from the mother the trauma related to this separation will be two fold, firstly the child is separated from the caregiver and person he/she formed an attachment with, and secondly, the child is separated from the only environment he/she is familiar with. The trauma caused by this separation is a further factor that highlights the debate, namely if it is in the best interest of an infant or young child to remain with its imprisoned mother after her incarceration.'

The unique relationship between mother and child, and the individual needs of each child make a policy decision on an appropriate age for separation very difficult to make. Some authors consider that it is impossible to define the "optimum age or stage at which a child should leave prison", because individual differences between children and the conditions in which they reside, would make such a recommendation "a gross overgeneralisation". ${ }^{50}$ The current South African law establishes, however, that a child may remain with his/her mother in prison up until the age of two, ${ }^{51}$ or

48 Committee on the Rights of the Child 2011 par 37. Although the Committee does not elaborate, its position might be the result of art 9(2) of the CRC, which requires that the separation of the child from his/her parents must be done by competent authorities, and be subject to judicial review.

49 Schoeman and Basson 2009 (NICRO) http://www.nicro.org.za/wp-content/uploads/2011/08/ Babies-behind-bars-summary.pdf 19.

50 Robertson 2008 Quaker United Nations Office: Human Rights and Refugee Programme www.quno.org 33.

51 Prior to the 2008 amendment, the Act permitted the mothers to keep their children with them in jail until the age of five. A study conducted by Schoeman and Basson, which showed the negative consequences of the prison environment on children's development, resulted in the age at separation being reduced from five years to two years (Schoeman and Basson 2009 (NICRO) http://www.nicro.org.za/wp-content/uploads/2011/08/Babiesbehind-bars-summary.pdf; and Hesselink and Dastile 2010 23(1) Acta Criminologica 65). Schoeman and Basson 2009 (NICRO) http://www.nicro.org.za/wp-content/uploads/2011/08/ Babies-behind-bars-summary.pdf 23, express the view that it is not in the best interests of the child to remain in prison with his or her mother due to the restrictive nature of the SA prison environment. They suggest an age of separation of 6 months (Schoeman and 
until such time as a suitable alternative placement can be secured considering the best interests of the child. ${ }^{52}$

Although the South African legislation provides an age limit in terms of keeping a child in prison, the framework is sufficiently flexible to accommodate individual needs. ${ }^{53}$ Policies provide that each case should be considered on its merits, and no "rigid directives" should apply. ${ }^{54}$ Rather, the decision must be based on an individual assessment of each case, and "[t]he best interests of the child shall always be a primary consideration". 55 This flexibility is also safeguarded by those provisions which make the separation of the child from his/her mother conditional on securing an appropriate placement for the child - rather than on the child attaining a certain age. ${ }^{56}$ Furthermore, the placement of the child with another person may only take place if a medical practitioner declares the infant "fit for placement".

Factors considered when determining whether the child should be allowed to stay in prison past the cut-off age, would include how much longer the mother is likely to be in prison, ${ }^{58}$ and what alternative care options are available for the child. ${ }^{59}$ Research in other jurisdictions indicates that prison officials decide in favour of maintaining the child in prison above the stipulated age, when the mother is approaching the end of her sentence - in order to avoid the trauma caused by separation, followed by a reunification very shortly thereafter. ${ }^{60}$ If the mother still has a lengthy sentence to serve, consideration should also be given to how far away from the prison the child might be placed.

Basson 2009 (NICRO) http://www.nicro.org.za/wp-content/uploads/2011/08/Babies-behindbars-summary.pdf 25) The rationale behind the amendment was that the first two years of life are critical for mother and child bonding, but allowing a young child to remain in prison after the age of two can be harmful for his/her development. Up to the age of two the child has the possibility to bond with the mother, and the bond between the mother and the child is considered sufficiently stimulating for the child; keeping the child in prison beyond that age, however, will make it difficult for the child to adapt to life outside the prison (Hesselink and Dastile 2010 23(1) Acta Criminologica 67).

$52 \mathrm{~S} 20(2)$ of the Act.

53 This was the intention reflected in the DCS in "White Paper on Corrections in South Africa" 2005 http://www.info.gov.za/view/DownloadFileAction?id=68870 (accessed 2011-12-20) [79] which indicates that policy dealing with female offenders with children must be "flexible enough for adjustment on the basis of proper assessment of the particular family circumstances of the child outside of the correctional centre, and alternative arrangements that can be made".

54 Par 15.1 of B-Order 1

55 Ibid.

56 Par 1.1. B-Order 1. The use of the word "or" in s 20(1) of the Act suggests though that separation of the mother and child can occur even before the child has reached the age of two, if an appropriate placement has been identified.

57 Par 10.3.2 of B-Order 1.

58 Robertson 2008 Quaker United Nations Office: Human Rights and Refugee Programme www.quno.org 20.

59 Black, Payne, Lansdown and Gregoire "Babies Behind Bars Revisited" 2004 89(10) Archives of Disease in Childhood 896897.

60 Robertson 2008 Quaker United Nations Office: Human Rights and Refugee Programme www.quno.org 20. 
The best interests of the child standard is an explicit criterion when deciding on the separation of the child from his/her mother and the placement of the child. ${ }^{61}$ The Infants and Mothers Policy requires that children be placed out as soon as possible, based on an individual assessment of each case. ${ }^{62}$ To minimize the negative impact of the separation on both the mother and the child - they have to be assisted to deal with the separation. ${ }^{63}$

As placement of children in prison with their mothers is seen as a temporary solution, ${ }^{64}$ the child must be placed out as soon as possible ${ }^{65} \mathrm{~A}$ time-limited plan for the integration of each infant into the community should be prepared. ${ }^{66}$ The drafting of the plan takes place with the involvement of the mother, relatives, and other important stakeholders. ${ }^{67}$ Social workers and the heads of prisons need to liaise with the pregnant prisoners/mothers, external welfare organizations and support system related to the child's birth or admission. ${ }^{68}$ There is a duty on the DCS to inform the Department of Social Development of the incarceration of a mother with an infant, in order to facilitate the placement of the child outside of prison. ${ }^{69}$ Amongst the factors to be considered in the drafting of the plan are the length of sentence, past history of incarceration, and the availability of a support system outside the prison. ${ }^{70}$ The placement of infants is arranged in consultation with the DSD. ${ }^{71}$ In South Africa it is common for alternative care for this group of children to be arranged with family members, or foster parents, and if neither of these options is available or suitable, then placement in a residential facility is considered. ${ }^{72}$ The suitability of alternative care arrangements for children separated from their imprisoned mothers has not yet been studied, although such research would be valuable for fully understanding the impact of mothers' incarceration on their dependent children.

\footnotetext{
Par 7.10 Infants and Mothers Policy.

Pars1.1 and 15.1 of B-Order 1.

Par 14.5. B-Order 1.

Par 1.1. B-Order 1.

Par 15.1. B-Order 1.

6 Par 14.1. B-Order 1.

67 Par 14.2. B-Order 1. See also par 1.2.7 which reads "Every child should be given the opportunity to grow up in their own family and where this is proved not to be in their best interest or not possible, a plan which provides for, inter alia, a life-long relationship in a family, is necessary and must be attended to by the multidisciplinary team, external professionals, the mother, relatives, etc."

68 Par 15.2. B-Order 1.

69 In 2010, the DCS launched the Imbeleko Project, with the intention of creating safe and friendly conditions for mother-child interactions within the prison environment. The Project also focuses on finding alternative placement for children older than two years of age, outside correctional facilities. This would be either with a family member or guardian chosen by the mother, or in the event where there is no suitable guardian, the child will be placed in a foster-care unit. The DCS assures that the child "would still maintain the psychological and emotional contact with the mother through arranged visitations" (Department of Correctional Services "Minister Launches a 'Model' Mother and Child Unit" 2011 http://www.dcs.gov.za (accessed 2012-01-20)).

70 Par 14.3. B-Order 1.

71 Par 15.6. B-Order 1.

72 Makhaye "Liberating Babies from Jail" 4 April 2010 City Press http://www.citypress.co.za/ SouthAfrica/Features/Liberating-babies-from-jail-20100424 (accessed 2012-01-03) [1].
} 
Research suggests that the quality of the relationship between the child and the outside world (including family and non-family members) is an important factor in strengthening the child's capacity to cope with the separation from his/her mother. ${ }^{73}$ It is debatable, however, whether the current regulatory framework facilitates the creation or maintenance of a quality relationship between the child and the significant "others" living outside the prison. Although the policy states that contact visits between the infant and other members of his/her family must be facilitated - no details are supplied about the frequency or duration of such visits. ${ }^{74}$ Visits in South African prisons are a maximum of forty minutes long, but in reality this time is often shortened to allow more prisoners to receive visitors. ${ }^{75}$ Correctional directives apparently dictate that family visits take place predominantly over weekends, which make contact problematic because at such times the prisons are managed with only half the personnel. ${ }^{76}$ These realities place a question mark over whether the current regulatory framework and its implementation give a meaningful opportunity to children living in prison with their mothers - to create quality relationships with those on the outside, and thus avoid significant trauma on separation. Arguably, a more flexible system should be designed.

\section{GENDER ANALYSIS OF THE LEGAL FRAMEWORK}

It is very seldom that states allow children to live in prison with their fathers. ${ }^{77}$ In South Africa, the legislative and policy framework allows only the mothers to bring their infants into prison. ${ }^{78}$ By contrast, the 2011 Day of General Discussion organized by the Committee on the Rights of the Child focused on the rights of children of incarcerated parents (note the genderneutral term) rather than on children of incarcerated mothers. ${ }^{79}$ This raises the question of whether the current South African framework might be discriminatory against fathers on the grounds of gender.

73 Parke and Clarke-Stewart "Effects of Parental Incarceration on Young Children" Working papers prepared for the "From Prison to Home" Conference, 30-31 January 2002 organized by US Department of Health and Human Services, The Urban Institute, 2001 http://aspe. hhs.gov/hsp/prison2home02/parke\%26stewart.pdf (accessed 2012-02-03) [3].

74 Par 12.3. B-Order 1.

75 Luyt "Imprisoned Mothers in South African Prisons with Children Outside of the Institution" 200816 European Journal of Crime, Criminal Law and Criminal Justice 299318.

76 Ibid.

77 Robertson 2008 Quaker United Nations Office: Human Rights and Refugee Programme www.quno.org 18. In Australia the policy does not distinguish between mothers and fathers in terms of allowing them to keep their children in jail. The Bolivian legal framework allows children to remain in prison with both mothers and fathers up until the age of six. Denmark seems to be the only Western European country allowing fathers to keep their children with them in prison. Spain provides a facility where children can live with their incarcerated parents, should both parents be in custody. See Rosenberg "Children Need dads Too: Children with Fathers in Prison" Quaker United Nations Office 2009 http://www.quno.org/ geneva/pdf/humanrights/women-in-prison/CNDT-English.pdf (accessed 2013-03-18) [4-5].

78 S 20(1) of the Act.

79 See, eg, that the summary of the proceedings of Working Group 1 on "Babies and children living with or visiting a parent in prison" refers repeatedly to children living with an incarcerated parent (supra fn 39 par 8 and further). When the discussion referred explicitly and exclusively to children living with their mothers in prison, the distinction is clearly drawn (see, eg, par 13). 
The South African Constitutional Court has in fact dealt with the differential treatment of incarcerated mothers and fathers, respectively, in President of the Republic of South Africa v Hugo, ${ }^{80}$ where a constitutional challenge was brought against the decision of the President to pardon only the mothers (and not the fathers) of children below the age of twelve. An argument was made that the discrimination was not unfair because the Presidential Act was aimed primarily at benefitting the children and not their mothers. Thus, as most primary caregivers of children are their mothers, the interests of children would be best pursued by releasing the mothers. ${ }^{81}$ The court criticized the argument, indicating that reliance on such generalizations could often constitute unfair discrimination. ${ }^{82}$ The court held:

"There will, doubtless, be particular instances where fathers bear more responsibilities than mothers for the care of children. In addition, there will also be many cases where a natural mother is not the primary care giver, but some other woman fulfils that role, whether she be the grandmother, stepmother, sister, or aunt of the child concerned. However, although it may generally be true that mothers bear an unequal share of the burden of child rearing in our society as compared to the burden borne by fathers, it cannot be said that it will ordinarily be fair to discriminate between women and men on that basis."

The court concluded that, in addition to reasons pertaining to penal policies and public interest, ${ }^{84}$ the purpose of the Presidential Act was best achieved by releasing the mothers: "[a]s many fathers play only a secondary role in child rearing, the release of male prisoners would not have contributed as significantly to the achievement of the President's purpose as the release of mothers".

In light of this effective protection argument put forward in President of the Republic of South Africa $v$ Hugo, and considering the age of young children currently being allowed to remain in prison with their mothers, it can be argued that the regulatory framework does not discriminate unfairly between mothers and fathers. As mothers continue, generally, to be the primary caregivers of children, the approach reflected in the Act and its implementing policies, might be defensible from an effectiveness perspective. ${ }^{86}$ It is uncertain, however, whether the effectiveness argument has been a determining factor in the drafting of the legal framework. According to the DCS, section 20(1) of the Act recognizes the "social significance of the maternal role of the mother in the family and in the upbringing of children". ${ }^{87}$ One may argue that such an understanding of section 20 of the Act is

\footnotetext{
1997 (4) SA 1 (CC).

President of the Republic of South Africa v Hugo supra par 37.

President of the Republic of South Africa $v$ Hugo supra par 39

83 President of the Republic of South Africa v Hugo supra par 37 per Goldstone $\mathrm{J}$ for the majority.

84 President of the Republic of South Africa v Hugo supra par 46.

86 A study by the South African Institute for Race Relations (SAIRR) showed that only $2.8 \%$ of South African children live with their father only; $40 \%$ are living with their mothers only; $35 \%$ live with both parents; and 22.6\% live with neither parent (Holborn and Eddy 2011 http://www.sairr.org.za/services/publications/occasional-reports/files/first-steps-to-healingthe-south-african-family-final-report-mar-2011.pdf 3.

87 Par 2 of the Infants and Mothers Policy.
}

85 Ibid. 
predicated on a generalization of the type which attracted the criticism of the court in President of the Republic of South Africa v Hugo. It is also contrary to the position currently embraced by courts - that decisions concerning children should be based on an individualized assessment of what is in their best interests. ${ }^{88}$ The current framework does not allow for such individualized assessment, since it precludes a father demonstrating that he is the primary carer of his child and thus performs the special role which the analysed framework seems to assume is played by the mother only.

Breastfeeding - perhaps the only inherently maternal-caring attribute could have been provided as a possible objective justification for the exclusion of fathers from the benefits and responsibilities arising from section 20 of the Act. ${ }^{89}$ However, the current legislative framework does not provide that breastfeeding is a condition for admitting children to be in prison with their mothers. Whilst this approach shows respect for mothers' autonomy, it also erodes the support for the current South African position that - by law - only mothers should be allowed to bring their infants into prison. The fact that breastfeeding is not the determining factor in deciding on the admission of a child with his/her mother in prison raises the question as to what other factors pertaining to the relationship between the mother and child are to be considered by officials when deciding whether to allow the child to join his/her mother in prison. Consistent with the Children's Act ${ }^{90}$ and the courts' jurisprudence, ${ }^{91}$ one may argue that the quality of the relationship between the mother and the child prior to incarceration should be a weighty factor. ${ }^{92}$ Only a nurturing mother-child relationship should be worthy of such strong protection by the law. But a quality relationship with one's child is not necessarily restricted to mothers. Research shows that a positive relationship between a mother and her child is not a given - but

88 In $S \vee M$ the CC held that "[a] truly principled child-centred approach requires a close and individualized examination of the precise real-life situation of the particular child involved" (par 24). In $A D$ v DW (Centre for Child Law as Amicus Curiae; Department for Social Development as Intervening Party) 2008 (3) SA 183 (CC), the court found that the best interests of each child must be examined on an individual basis and not in the abstract (par 55). Support for this approach is also found in academic writing. Bonthuys "The Best Interests of Children in the South African Constitution" 2006 20(1) International Journal of Law, Policy and the Family 3) asserts that in South Africa, applications of the best-interestsof-the-child principle "stress the fact that the best interests of a particular child would depend on the surrounding circumstances and that each case should be decided on its own merits". Skelton states that: "a truly child-centred approach requires an in-depth consideration of the needs and rights of the particular child in the 'precise real-life situation' he or she is in. To apply a pre-determined formula for the sake of certainty, irrespective of the circumstances, would in fact be contrary to the best interests of the child" (Skelton "Constitutional Protection of Children's Rights" in Boezaart (ed) Child Law in South Africa (2009) 283).

89 The existing studies do not indicate the prevalence of breastfeeding amongst incarcerated mothers and provide no insight into the weight attached to breastfeeding or the mother's intention to breastfeed - in the decision to allow the child to join or remain with the mother in prison.

90 S 7 of the Children's Act - which provides some guiding criteria for the application of the best interests of the child - includes amongst those the nature of the relationship between the parent and the child (a); the attitude of the parent towards the child and the exercise of parental responsibilities (b); and the capacity of the parent to care for the child (c).

91 In $S \vee$ Howells; $S \vee M$; and $S \vee S$.

92 This line of reasoning does not apply, of course, to pregnant women - who should be given the opportunity to create a bond with their child. 
requires effort and needs to be built. ${ }^{93}$ There is no reason to assume that a father cannot build an equally strong relationship with his child - especially if the father is the primary or even the sole caregiver of the child.

South African jurisprudence has recognized that the relationship between a primary caregiver and a child is special. The current jurisprudence contains legal guarantees to prevent or soften the impact of lawful interference by the State with the parental care provided by the sole primary caregiver of minor children. ${ }^{94}$ Notably, this jurisprudence is gender-neutral and benefits primary caregivers - mothers or fathers - and their children. Furthermore, South African law and jurisprudence have moved away from associating primary care - even for young children - with mothers only. The Children's Act, for example, envisages fathers with parental responsibilities playing a more important role in their children's upbringing. ${ }^{95}$ Furthermore, men can - by themselves or as a homosexual couple - adopt children or enter into surrogate-motherhood agreements. ${ }^{96}$

For the above reasons, a critical, gender-based assessment of the current framework should take place. There are, of course, major implications for reforming the legal framework and allowing children to join their fathers in prison. First, there will be concerns that some fathers might try to "abuse the system". South African jurisprudence has, however, developed mechanisms to guard against potential abuse - both by mothers and fathers. The sentencing jurisprudence could be used as a starting point in this regard. Because it is the special relationship between the primary caregiver and the child which is sought to be protected, a policy could limit the possibility of bringing children into prison to fathers who can show that they are the primary caregivers of the children concerned. ${ }^{97}$ Following the reasoning

93 Schoeman and Basson 2009 (NICRO) http://www.nicro.org.za/wp-content/uploads/2011/08/ Babies-behind-bars-summary.pdf 22.

94 In $S \vee$ Howells supra $683 \mathrm{C}-\mathrm{F}$, the court asked the then Department of Welfare and Population Development to ensure that children are well cared for during their mother's imprisonment, that they maintain contact with their mothers through regular visits, and that they are successfully reunited with the accused after her release from prison. In $S \vee M$ the court found that s 28(1)(b), read together with s 28(2), requires the law to "make best efforts to avoid, where possible, any breakdowns of family life or parental care that may threaten to put children at increased risk" (par 20). In $S \vee S$ the court ordered the DCS to take measures that a social worker visits children regularly to ensure that they are well-cared for (par 66 and 68.4).

95 S 20-21. This is consistent with South Africa's obligations under Article 18 of the CRC, which requires that the responsibilities of both parents are recognized. In: Louw "Single Fathers Fight Back" 11 February 2013 The Times http://www.timeslive.co.za/thetimes/2013/ $02 / 11 /$ single-fathers-fight-back, it is indicated that in January 2013 , the Office of the Family Advocate received 1400 applications from parents seeking greater access to their children. However, a South African Institute of Race Relations study showed that the proportion of absent but living fathers in South Africa was 48\% in 2009 (Holborn and Eddy 2011 http://www.sairr.org.za/services/publications/occasional-reports/files/first-steps-to-healingthe-south-african-family-final-report-mar-2011.pdf 4).

96 Chapter 15 of the Children's Act - on adoptions - does not prohibit, explicitly or implicitly, single males or homosexual couples from adopting children (see s 231). Chapter 19 of the Children's Act - on surrogate motherhood - does not prohibit a surrogate agreement between a single male or homosexual couple, eg, with the surrogate mother (see s 292 and 293).

97 Arguably, the same criteria should apply to mothers whose children were born prior to incarceration. 
reflected in the same jurisprudence, ${ }^{98}$ should the other parent be available and able to take over the primary care responsibilities, then the father should not be allowed to bring the child to be with him in prison, save for exceptional circumstances.

A second consequence of reforming the legal framework - and perhaps of more significance - is the lack of adequate facilities, which might prove to be the most serious obstacle to allowing children to join their fathers in prison. While some South African prisons have been adapted to allow children to join their mothers, the same cannot be said about male prisons. Clearly, no child should be allowed to join a parent in custody if the custody conditions are likely to be detrimental to his/her development. ${ }^{99}$ But, as the legal framework stands, there is no indication that the decision to allow only mothers to bring their children into prison is predicated on an acknowledgement that the current situation of the male correctional services would not allow the same benefit to the fathers. Nor is there an indication in the relevant policies that it would be too expensive for the DCS to create specialized units in male correctional facilities. In any case, the DCS does not seem to rely exclusively on special units to accommodate children who join their mothers in prison. The DCS in fact allows children to join their mothers in correctional facilities where mother-and-baby units do not exist subject to offering them a humane environment which is responsive to their needs. ${ }^{100}$ Therefore, it seems that the strongest rationale for allowing mothers to bring their children to be with them in prisons - identifiable in the relevant policies - is the special relationship between mothers and children. ${ }^{101}$ As discussed above, this is a problematic ground for justifying a differentiation in the treatment of imprisoned mothers and fathers, and it leaves the current legal framework open to challenge for unfair discrimination on grounds of gender. ${ }^{102}$

$98 \quad S \vee S$.

99 This is also the position of the Committee on the Rights of the Child, which includes the available facilities as a factor in determining whether it is in the best interests of the child to join a parent in prison.

100 See discussion in par 2 above. Par 4.5 of B-Order 1 reads: "Where a correctional centre/prison does not provide for a mother-and-child unit/single accommodation for a mother and her child, the Head of the Prison/correctional centre is responsible for initiating satisfactory arrangements to accommodate them in a humane environment and taking into consideration their specific needs, i.e. privacy."

101 DCS Infants and Mothers Policy par 2.

102 It can be argued that the policy discriminates on the grounds of gender (s $9(3)$ of the Constitution) between primary care-giving mothers and primary care-giving fathers of young children. This challenge could also be phrased from a children's rights perspective - the policy discriminates against children on the basis of the sex of their primary caregiver (that is, the father). Such discrimination is prohibited by art 2(1) of the CRC. The South African jurisprudence requires development in this regard, and arguably there is scope to do so under the equal protection by the law provision in s 9(1) of the Constitution. Furthermore, it can be argued that the current policy might be discriminatory on the basis of sexual orientation (s 9(3) of the Constitution) - as homosexual parents are not given the opportunity to preserve their bond with their children in the event of incarceration. 


\section{SELECTED COMPARATIVE ASPECTS}

The above analysis shows that there are certain concerns pertaining to the admission and the separation of mothers and infants - and the gender implications of the current framework. The comparative analysis below provides examples of how other jurisdictions have dealt with similar issues. These examples could be considered should legal reform of the current framework be envisaged. ${ }^{103}$ Two jurisdictions have been selected for comparative purposes - England and Western Australia. Both are developed, industrialized jurisdictions, and the authors are aware that their socio-economic conditions are very different from those in South Africa. This does not detract, however, from the comparative relevance of their policies. Like these two jurisdictions, South Africa has a written policy dealing with children of incarcerated mothers and this policy is predicated on the respect for the rights of children and their mothers, especially. The special relevance of the policies in the two jurisdictions emanates from the fact that their comprehensive, rights-based policies address specifically the areas found to be problematic in South Africa.

\section{England}

The Mother and Baby Units (MBUs) Instruction (the Instruction), which currently applies in England and Wales, contains detailed procedures and criteria for the admission of a mother and her baby in an MBU. ${ }^{104}$ As far as the procedures are concerned, there is a duty on prison officials to ensure that all pregnant women and mothers are given the opportunity to apply for a place in an MBU. A booklet has been created to this end - "All about Mother and Baby Units" - which must be made available, and be accessible, to those potentially interested. ${ }^{105}$

The woman wishing to apply for a place in an MBU, must be referred to the Mother and Baby Liaison Officer, who will assist her in completing the application, and will give her advice. ${ }^{106}$ The mother needs - inter alia - to provide information about the situation of the father: whether the child lives with the father or whether the father has contact with the child, and whether the father supports the mother's application. The mother is also asked about the alternative arrangements she has made for the child, including if the child is to exit prison before her. ${ }^{107}$ The Liaison Officer then compiles a file containing a social services' report, a security report, medical reports, a

103 The Infants and Mothers Policy provides for its annual revision in order to assess the effectiveness of its implementation. Par 11 of the Policy reads: "The policy for infants and mothers will be reviewed annually to determine the extent of application and identify gaps, if any, as well as to ensure compliance with other policy frameworks, including legislation and international requirements."

104 Ministry of Justice, PSI 54/2011, effective 1 October 2011 (expiry date 1 October 2015) http://www.justice.gov.uk/offenders/psis/prison-service-instructions-2011 (accessed 201303-20).

105 Par 2.1.1.

106 Par 2.1.3.

107 Annex A. 
personal officer report, and a probation report. ${ }^{108}$ These reports - together with the mother's application - are analysed by the Admission Board, ${ }^{189}$ with the participation of the mother. ${ }^{110}$ The Admission Board then makes a recommendation ${ }^{111}$ to the Governor/Director of the prison. ${ }^{112}$ The mother has the right to appeal the decision not to grant her a place in an MBU - using first the Prisoner Complaints system ${ }^{113}$ and the legal system thereafter.

For a positive recommendation to be made, ${ }^{114}$ the following criteria must be met:

"It is in the best interest of the child/children to be placed in a Mother and Baby Unit.

The applicant is able to demonstrate behaviours and attitudes which are not detrimental to the safety and well being of other residents.

The applicant has provided a urine sample which tests negative for illicit substances.

The applicant is willing to refrain from substance misuse.

The applicant is prepared to sign a standard compact, which may be tailored to her identified individual needs.

The applicant's ability and eligibility to care for her child is not impaired by poor health, or for legal reasons such as the child being in care or on the Child Protection Register as a result of the applicant's treatment of that child, or other children being in care."

Although important, the best interests of the child are not the only factors to be considered when deciding on an admission. ${ }^{116}$ Acknowledging their responsibility for the safety and adequate development of other children, the criteria for admission require the mother to have and maintain appropriate behaviour. ${ }^{117}$ The mother's ability and eligibility to care for the child are also factors to be taken into account when recommending an admission. ${ }^{18}$ The Admission Board will consider whether the mother was the primary caregiver prior to custody, and if not, the reasons for such a situation. ${ }^{119}$ The length of the mother's sentence must also be considered when making the decision. ${ }^{120} \mathrm{~A}$ long sentence need not be an obstacle to allowing the child to

108 Par 2.1.4.

109 Consisting of an independent chair, manager of the MBU, line manager with responsibility for the MBU, the applicant plus a friend or a personal officer, and a social services and/or probation officer.

110 Par 2.2.4-2.2.5. The mother must be given an opportunity to participate in the decision of the Admission Board - in person, via video link, or by making a detailed written submission.

111 The records of the meeting must be kept in detail, and must indicate the reasons for a decision, as well as whether the decision was unanimous or not (par 2.2.10).

112 Par 2.1.6 and 2.2.3; and par 1.4.

113 Par 2.1.8. See also par 2.2.10.

114 There are several types of decisions which can be made on the mother's application: temporary admission, emergency temporary admission, full admission, conditional refusal, and full refusal. This variety of possible decisions allows for flexibility in adapting the decision to the circumstances of each case (par 2.2.12). This paragraph contains definitions of each type of admission and the circumstances under which they are suitable.

115 Par 2.2.5.

116 Par 1.4a.

117 Par 2.2.1.

118 lbid.

119 Annex B.

120 Par 2.2.11. 
remain in prison with the mother for a short period of time - should that be in the child's best interests. Relevant factors to consider in such cases include "allowing the mother to form some relationship with the child for the future; allowing breast feeding (expressing may be an alternative); and giving time for alternative care arrangements to be made". ${ }^{12}$

Unlike in South Africa, the existence of a suitable arrangement for the child to live within the community is not an obstacle to admitting the child to be in prison with his/her mother. If the envisaged alternative arrangements are more favourable to the child than admission to the MBU, the Admission Board may consider whether it is in the best interests of the child to be placed in the MBU - especially if, in the light of the length of the mother's sentence, they will not leave the prison at the same time. ${ }^{12}$

Children accompanying their mothers into prison are considered "in need" according to Department of Health guidelines (not social services) - and thus require "regular review of the child's and mother's progress on the unit". ${ }^{123}$ If separation is to occur, the planning is to start immediately. Priority is to be given to the mother's choice of potential carers - provided that Social Services check these persons' availability and suitability. If such care is not available, foster care must be arranged.

There is recognition that children need to maintain ties with the outside community, in order to maintain family relations and to facilitate the child's re-adjustment to life outside prison. Thus "Governors/Directors must have systems in place which recognize the need for children to spend time in the community". ${ }^{125}$ Furthermore, the links with the community should not be adhoc, but rather systematic. In order to maintain links with outside communities, children may stay over at family members - for example. ${ }^{126}$ It is the responsibility of the Governor/Director to ensure that, if the child visits the community, the person to whom the child is handed over, is "suitable and appropriate to care for the child, and in particular, do[es] not present a risk of harm to that child". ${ }^{127}$ Persons who volunteer to take the child out of prison, or those nominated by the mother to care for the child in the community, must be cleared by prison authorities - regardless of whether they are relatives or not. ${ }^{128}$

A separation plan is a condition for admission into the MBU and is agreed between the mother and the multi-disciplinary team on her arrival in the MBU. ${ }^{129}$ The mother must nominate "two appropriate and responsible people" to ensure the continued care of the child - should a separation occur. ${ }^{130}$ Importantly, the Social Services must check the suitability and availability of the nominated persons in terms of caring for the children in

\footnotetext{
Par 2.2.12.

Par 2.2.2.

Par 3.1.1.

4 Annex D.

Par 5.1.6.

Par 5.1.7.

Par 5.1.11.

Par 5.1.12.

Par 6.1.1.

Par 6.1.2.
} 
their mother's absence. ${ }^{131}$ The nominated persons, including family members, must be checked, and they must not have been convicted of violence or sexual offences against children. ${ }^{132}$

If the mother contests the intention to separate her from her child, and when the case is "a sensitive and difficult one", an Independent Separation Board must be convened. ${ }^{133}$ The purpose of the Independent Board is to review situations where there is disagreement between the mother and what the officials consider to be in the child's best interests, and in situations when a separation was decided because of the mother's behaviour - which is considered to affect the atmosphere in the MBU adversely. ${ }^{134}$ The mother will participate in the meetings of the Separation Board, ${ }^{135}$ and the social services workers will represent the best interests of the child. ${ }^{136}$

\section{Western Australia}

The situation of incarcerated mothers and their children is addressed in the 2007 Policy Directive 10 Prisoner Mothers/Primary Carers and their Children (the Policy). ${ }^{137}$ Notably, the policy refers to mothers as well as the primary carers (female or male) of children of a certain age. ${ }^{138}$ The Policy provides a wide range of options for allowing children to create or maintain bonds with their primary caregivers. This includes residence, and extended and overnight stays in the prison where the primary carer is incarcerated. ${ }^{139}$ The residence programme (that is, the child resides with the mother in prison) is intended for children aged twelve months or younger, or for children aged four years old or younger, whose mothers are incarcerated in minimumsecurity facilities. ${ }^{140}$ Extended stays and overnight stays are used especially to enable older children to maintain regular contact with their mothers. ${ }^{14}$

131 Ibid.

132 Par 6.1.3.

133 Par 6.2.6.

134 Par 6.2.8.

135 Par 6.2.10.

136 Par 6.2.12.

137 Government of Western Australia, Department of Corrective Services, 2007 http://www. correctiveservices.wa.gov.au/_files/prisons/adult-custodial-rules/policy-directives/pd-10.pdf (accessed 2013-05-19).

138 A "mother" is defined as a "biological mother or primary carer". A primary carer is defined as "an individual who is the main person responsible for the custody or care of a child or children". The extension of the policy to primary carers seems to be motivated by a desire to accommodate various cultural practices pertaining to child-rearing. Par 4 of the Policy, titled "Relationship of Child to Carer", reads "Where it has been established that a significant primary-caring relationship exists, prisoners may apply to the Superintendent to have the child for whom they have been caring stay with them for overnight stays or extended day visits. This flexibility is required to accommodate cultural issues in relation to child rearing."

139 The "Purpose" of the Policy reads: "To provide authority for the implementation and operation of the child residence, extended day and overnight stay programs enabling primary care givers to maintain or establish bonds and relationships with their children."

140 Par 3.1.1 and 3.1.2 of the Policy.

141 A regular extended day's stay is available for primary carers and children up to the age of twelve (par 3.2.1 and 3.2.2 of the Policy). Overnight stays with primary caregivers are allowed in a secure prison until the child is six years old (par 3.3.1 of the Policy), or in a minimum-security environment until the child is twelve years old (par 3.3.2 of the Policy). 
Primary carers may apply for overnight stays or extended day visits for their children, if "it has been established that a significant caring relationship exists".

The applications for various forms of stay in prison are dealt with by the prison Superintendent. He/she may decide not to proceed with the application under the following circumstances:

"6.1.1.1 Psychiatric reports indicate the applicant suffers from mental illness and is unable to care for the child.

6.1.1.2 The applicant is actively engaged in self harm or displays suicidal behaviour.

6.1.1.3 The applicant is displaying violent behaviour in the prison environment.

6.1.1.4 The applicant is regularly/routinely testing positive to non-issued substances.

6.1.1.5 The maintenance of the custody of the prisoner may be put at risk.

6.1.1.6 It is considered the security of the prison may be threatened.

6.1.1.7 The Superintendent believes he/she is unable to segregate the child from prisoners who present a threat to their safety, or:

6.1.1.8 The demands of the prison population count do not allow the capacity to set aside a particular space for the child residence program.

6.1.1.9 The Superintendent is unable to provide a facility that is suitable."143

The application will be assessed by a Child Care Management Committee, ${ }^{144}$ which makes recommendations to the Superintendent. The Committee will be presented with reports dealing, inter alia, with: the mother's criminal record and social history; the mother's capacity to care for the child in a prison setting; any family court orders; medical issues; availability of appropriate prison accommodation and facilities; availability of alternate carers in the community, ${ }^{145}$ who have been assessed and approved; and prior contact between the mother and the child (for example, whether the applicant has been the primary carer of the child concerned). ${ }^{146}$ If an application is denied, the inmate is informed and is also given reasons for the decision. The prisoner has the right to appeal. ${ }^{147}$

The accommodation where the children reside needs to be reviewed to ensure that children live in places that are fit for them. ${ }^{148}$ The separation of the mother or primary carer and the child resident occurs when the child reaches the maximum age for being allowed to reside in prison. ${ }^{149}$ On separation, the care of the child must be ensured by "an approved alternate

142 Par 4 of the Policy.

143 Par 6.1.1 of the Policy.

144 For its composition, see par 6.3.1 of the Policy.

145 The availability of parental care in the community does not seem to be an obstacle to admitting children in a residential programme with the custodial parent. This is implied in the fact that a care plan for a resident child must include a "schedule of visits to any noncustodial parent in the community" (par 7.3.4 of the Policy).

146 Par 6.2.1 of the Policy.

147 Par 6.5 of the Policy.

148 Par 24 of the Policy.

149 Par 10 of the Policy. 
carer". ${ }^{150}$ Similarly, a child's temporary leave from the prison must also take place into the care of an approved alternate carer. ${ }^{15}$

To conclude this brief review of policies in two foreign jurisdictions, it can be noted that these jurisdictions have comprehensive policies for dealing with mothers or primary carers incarcerated with their children. Their comprehensive admission criteria and procedures, the safeguards regarding the placement of the child on separation, as well as some gender-related aspects, make the two policies useful sources of inspiration for South African policy-makers. This is discussed further below.

\section{Comparative analysis}

In terms of facilities for inmate mothers and their children, unlike in South Africa, in England mothers with their babies can only be accommodated in specially-designed MBUs, which are adapted for the needs of children, and offer an environment conducive to their development. A similar approach is taken in Western Australia, whose policy - although it makes no reference to specialized units - indicates that a request by a primary caregiver to be accommodated in prison with a child may be declined should the prison administration not be able to provide an adequate environment. The approach taken by England and Western Australia alleviates, to a certain extent, the concerns that the environment to which children may be exposed is harmful. The South African policy does not explicitly refer to potential limitations in allowing mothers to bring their children to be with them in prison due to the DCS being unable to provide an environment conducive to child development. The DCS should consider including the availability of a place in an MBU or in a correctional centre where an adequate environment can be provided for the mother and the child, as an explicit criterion for the admission of an infant into prison to be with his/her mother. Although this might lead to fewer mothers being able to bring children with them into prison, it will mitigate the negative impact of an inadequate environment on children who are housed outside specialized units.

The admission provisions in both the English and Western Australian policies are quite detailed - making them much clearer and more predictable than the South African provisions. In England, there are clear provisions requiring that pregnant inmates or convicted mothers receive the necessary information about MBUs. In this manner, the mother becomes fully aware of the type of environment that her child would reside in, as well as of the temporary nature of such an arrangement. Both policies contain detailed indication of the materials which the decision-makers should have available in order to make a decision about the admission. The English policy is notable in its provisions to safeguard the mother's involvement in the decision-making process relating to admission.

The criteria for the admission of the child with the mother or primary carer - as the case may be - are clear both in England and Western Australia. They reflect the need to build and preserve the bond between the

150 Par 14 of the Policy.

151 Par 15 of the Policy. 
mother/carer and the child, without compromising the interests of others and the purpose of the law enforcement with regard to mothers' criminal behaviour. Both foreign policies contain an indication that the best interests of the child is not the paramount consideration when the safety and security of the prison is concerned. ${ }^{152}$

In both foreign examples, the existence of suitable alternative care - or even parental care - on the outside, does not preclude a finding that it is in the best interests of the child to be admitted to be with his/her mother or primary carer in prison. The South African policy differs in that a child is to be admitted with the mother - only if no suitable care is available outside prison. ${ }^{153}$ Arguably, the trenchant position of the South African policies is inconsistent with the individual-centred approach to the application of the best interests of the child standard. It also seems to be inconsistent with the basic rationale of the legal framework - the recognition of the special role of mothers in the lives of their children.

The English Instruction gives priority to the mother's choice of a suitable carer for her child, during her imprisonment. In the absence of suitable arrangements made by the incarcerated mother, the State is to place the child in foster or other type of care. Arguably this avenue could be considered by South African authorities - especially in light of section 32 of the Children's Act, which makes provision for the care of a child by persons not holding parental responsibilities and rights. This would alleviate the pressure on the formal, state-care system, ${ }^{154}$ and would allow the child to be cared for by a person whom the mother personally trusts. However, this is not to say that we advocate that a placement be made exclusively at the discretion of the mother. In England, the prison authorities must establish the availability and suitability of the person designated by the mother, and in Western Australia the release of the child from prison prior to the mother's release, must take place into the care of an approved carer. The same could be done in South Africa, considering that B-Order 1 mentions that a wide range of actors is to be involved in the placement of the child ${ }^{155}$ - who can be called upon to assess the suitability of the mother's choice of carer.

The Western Australian policy is notable in its application not only to mothers, but more generally to primary carers. Two consequences arise

152 Par 1 of the Western Australian Policy.

153 Par 3.0 of B-Order 1. The South African framework does refer in certain places to the father, or to the members of the family. A literal interpretation of the policies would lead one to the conclusion that the child is to be admitted with the mother if neither the father nor the rest of the family can provide suitable care. The Western Australian Policy refers to visits to a noncustodial parent on the outside.

154 Eventually, such carers might want to have their relationship with the child formalized, in order to access a foster-care grant.

155 DCS social workers, Department of Social Development social workers, external organizations. Their role, however, is not always clear. It is not clear, eg, what is meant by an external organization. Also, par 15.6 of B-Order 1 indicates that the placement of the child takes place "in consultation with the Department of Welfare", whilst par 15.7 states that certain information relevant for arranging the placement must be provided by the DCS to the Department of Welfare. It is thus unclear which of the two departments has the main responsibility for ensuring the placement. 
from this. The first is that the policy is gender-neutral, ${ }^{156}$ and thus also applies to fathers who can prove that they are the primary carers of their children. To this extent, Western Australia is an exception, because not many jurisdictions seem to allow children to reside in prison with their fathers. ${ }^{157}$ A second consequence arising from the inclusion of primary carers in the policy, is that primary carers who might not be the biological parents of the child, could apply to have children with them in a correctional centre. So drafted, the policy recognizes that it is not only mothers - but also fathers and other primary caregivers - who can play a special role in an individual child's life. The gender-neutral approach of the policy is perhaps facilitated by the variety of the programmes provided for in the policy. Thus, when inclusion in a full residential programme is not possible, ${ }^{158}$ the inmates and prison officials can explore extended day or overnight stays. This way, although the children might not be able to reside with their primary carers, they will have an opportunity to preserve their strong bond in other ways.

Considering the variety of care options in South Africa, and especially because many children do not live with their biological mothers, ${ }^{159}$ it seems rational to extend the application of the South African policy to other primary carers. Two options can be explored by the DCS. One is to define the term "mother" to mean the biological mother or any other female primary carer. The second option would be to extend the application of the policy to primary caregivers of both genders. Should this latter option be followed, the placement of a child with a male primary caregiver in a prison which does not provide adequate facilities for a child, could be prevented - given that the availability of adequate facilities where the male primary caregiver is incarcerated, is a criterion for the admission of the child. In this way, the individualized assessment of the best interests of the child is ensured at two levels: one, with regard to the relationship between the male carer and the child; and second, with regard to the potential impact on the individual child of existing conditions in the centre where the carer is incarcerated.

156 Although the gender-neutral position has support amongst most Australian states, not all seem to be implementing it. Relevant paragraphs of the Standard Guidelines for Corrections in Australia (Revised 2004) reads: "2.54 Children and infants should be allowed to reside with their primary care giver in prison only after the Administering Department is satisfied that it is in the best interest of the child/ren to do so and there is no mechanism for the primary care giver to complete her/his sentence in the community (for example via home detention). 2.55 The accommodation for primary care givers and their children should, wherever possible, be domestic rather than custodial." http://www.correc tiveservices.wa.gov.au/ files/about-us/statistics-publications/students-researchers/guide

lines-for-correc tions-aust.pdf (accessed 2013-03-18). However, the Queensland legislation refers exclusively to female prisoners (but not only to mothers). S 29 of the Corrective Services Act, 2006 (Queensland) refers to female prisoners being able to bring children to prison (either their biological children or children entrusted into their custody by a court). Interestingly, the application for the accommodation of the child can be done by the female prisoner, as well as a child-protection executive http://www.austlii.edu.au/au/legis/qld/ consol_act/csa2006221/s29.html (accessed 2013-03-18).

157 See fn 77 above.

158 As a result of inadequate facilities, for example.

159 Holborn and Eddy 2011 http://www.sairr.org.za/services/publications/occasional-reports/ files/first-steps-to-healing-the-south-african-family-final-report-mar-2011.pdf 3. 


\section{CONCLUSIONS AND RECOMMENDATIONS}

Although the best option for children is to avoid the incarceration of parents convicted of crimes, in some cases this is impossible. When the convicted parent has children - especially very young children - a difficult situation arises with regard to the provision of care during parental incarceration. As discussed in this article, South African law and policy-makers have opted to allow mothers of children below the age of two to apply for permission to bring their children to be with them in correctional centres. The accommodation of mothers with children should take place - as is explored in section 2 of this article - in a MBU or an environment which is humane and not harmful for the child. Furthermore, as is discussed in section 4 of this article, it does not seem possible for fathers to apply for permission to bring children with them into correctional centres.

Despite its shortcomings, the current South African legal framework does have some positive aspects. Amongst the most important ones is that, overall, it is commendable that the state is trying to ensure that mothers who wish to foster their relationship with their infants are given the opportunity to do so. Despite other competing concerns in correctional services, ${ }^{160}$ financial resources have in fact been allocated for creating MBUs to accommodate at least some of the mothers wishing to bring their children into prison with them. The standard of services which the DCS aspires to provide in the MBUs, would no doubt be adequate to alleviate concerns that children joining mothers in prison would be faced with an environment which is harmful to them.

The current South African legal framework, however, was found to be wanting in certain aspects pertaining to the admission of children and separation from their mothers, as well as on grounds of gender. The admission criteria are insufficiently detailed and do not include a requirement that a child should only be admitted with his/her mother should that be in the child's best interests. The quality of facilities which de facto can be offered by DCS to children living with their mothers in prison is not an admission criterion. This creates the risk that the DCS - although acting in good faith and with good intentions - might allow children to reside in facilities which are inadequate to meet their needs. This point is relevant - especially for those children and their mothers who are not housed in MBUs. Furthermore, the policy is inconsistent with regard to judicial review of DCS decisions, in that a contested decision not to accede to the mother's request to bring a child with her into prison, does not need to be referred to a children's court unlike a contested decision to separate the mother from the child.

There is a lack of sufficient opportunities for the infant living in prison with his/her mother to create strong bonds with people outside the prison (see section 3). Research has stressed that such strong bonds are needed in

160 Overcrowding, shortage of personnel, and poor maintenance, seem to be at least some of the problems confronting the correctional system (See Republic of South Africa, Judicial Inspectorate for Correctional Services "2010/2011 Annual Report (Treatment of inmates and conditions in Correctional Centres)" 13; and Republic of South Africa, Judicial Inspectorate for Correctional Services 2011/2012 Annual Report 34-35. Both reports http://judicialinsp.dcs.gov.za/Annualreports/annualreport.asp (accessed 2012-03-23). 
order to facilitate the child's adaptation to a new environment - once released from prison ahead of his/her mother.

The gender critique in section 4 showed that the current South African legal framework might be discriminatory against men. It was shown that a differentiation between the treatment of mothers and fathers, based exclusively on the existence of a special bond between mothers and infants, is untenable - since fathers who are primary caregivers may develop similarly strong bonds with their children. No other reason for the differentiation could be identified in the current framework. The emphasis on an individual assessment of the best interests of the child in jurisprudence puts the current legal framework at odds with the constitutional principle of the paramountcy of the best interests of the child. The flat denial of the possibility of any fathers bringing their children with them into prison, prevents an individualized assessment of the child's best interests.

A few recommendations can be made in the light of the analysis conducted above. Some recommendations require policy reform, while others may be followed within the current framework.

The criteria for the admission of the child into prison - to be with his/her mother - should be clarified and should include the principle that an admission should take place only if this is the child's best interests. The term "mother" should be defined in the policies, so as to indicate whether the policy extends to adoptive, foster mothers, or even persons caring for children informally. The law will then provide equal protection to all females who might have a strong bond with a child. The same can be achieved by replacing the term "mother" with "primary caregiver" - and the implications of such a change are discussed in the gender perspective below.

The criteria for admission should indicate that admission can only take place if the DCS is able to provide an environment adequate for mothers and children. Arguably, the Judicial Inspectorate for Correctional Services could play a more active role in monitoring the conditions of detention for both mothers with children. ${ }^{161}$ Following the English example, a formalized system should be explored for informing the mother about the possibility of bringing her young child to be with her in prison, and of the conditions of incarceration to which the child might be exposed to, if admitted. The policy should also be redrafted to indicate explicitly that the refusal to admit a child to be in prison with his/her mother can be challenged in court. The mother should also be informed of her right to approach a court to challenge the decision not to admit her child, or to separate her from her child. The documentation used to make a decision about admission, should be specified in the policies - to alleviate the risk of arbitrary decisions based on insufficient information, being made. We suggest that the sentencing reports required by the $S \vee M$ case form part of such documentation.

With regard to separation and placement, more flexibility is required by DCS in order to allow children to create strong bonds with the outside

161 The 2011/2012 Annual Report of the Inspectorate indicates that the conditions of detention of mothers with infants are inspected. No detail is, however, provided in the report on the finding of such inspections. See, Republic of South Africa Judicial Inspectorate for Correctional Services, 2011/2012 Annual Report 33. 
community. Adjustments to prison-visiting times and the possibility of children's extended stay in the community, could be investigated. Following the English and Western Australian examples, the release of the child to any person outside the prison, must be done only after that person's suitability has been established by the DCS or DSD.

On the gender aspect, we believe that the policy framework should be revised. In the light of the increased recognition of the role of fathers in the Children's Act, and of the current jurisprudence which places great emphasis on an individualized assessment of the best interests of the child - it is necessary, at a minimum, for the State to provide a constitutionally acceptable reason for allowing mothers to bring their young children to be with them in prison, whilst at the same time denying the same possibility to fathers who might have equally strong bonds with their children. Should the State intend to extend the application of the policy to fathers, we suggest the replacement of the term "mother" in the current legal framework, with the term "primary caregiver" - which encapsulates better the objective of the policy: to serve the interests of the children. ${ }^{162}$

Arguably, the extension of the policy to male primary caregivers will not be too difficult for the State. Given the small number of fathers who assume the role of primary caregiver of their children, it is unlikely that many men would qualify for the application of the policy. Furthermore, concerns regarding the quality of conditions in male prisons can be dealt with by inserting in the admission criteria, a requirement that the admission of the child with an inmate can only take place if the DCS can provide an adequate environment for the child. ${ }^{163}$ This is not an exercise in cynicism - arguing for benefits for male prisoners only to later explore ways to curtail those benefits - but rather, it is an attempt to suggest a viable solution which responds to the needs of individual children.

162 The DCS will then need to establish whether the applicant is indeed the primary caregiver, or not. It has to be considered, however, that some parents are not the primary caregivers, for reasons beyond their control, and this should not disqualify them in terms of an application to have a child join them in prison. The English policy captures this concern requiring the decision-makers to obtain information about the reason for the mother not being the primary caregiver.

163 This approach is followed in Western Australia, as is discussed in par 52 and 53 above. 